\title{
Bildbäume und Baumbilder
}

\author{
Erhard Taverna
}

Unter dem Titel «Einfach komplex - Bildbäume und Baumbilder in der Wissenschaft» ist im Museum für Gestaltung in Zürich bis am 4. September 2005 eine interessante Ausstellung zu sehen. «Eine Ausstellung über Dinge, die wie Bäume aussehen.» Die Schau ist ein Teil des Festivals Science et Cité + Brain Fair 2005 und in Zusammenarbeit mit dem «Centre for Visual Studies» der Universität Oxford entstanden.

Keine Sprache kommt ohne Bilder aus, auch nicht die der Wissenschaft. Treppen, Säulen, Zakken, Scheiben, Pyramiden und Kreisdiagramme sind längstens Allgemeingut. Der Baum ist in allen Kulturbereichen das am häufigsten und vielseitigsten verwendete Bild. Als Weltenbaum und Stammbaum, als Strukturprinzip und Denkfigur vereinigt er Kunst, Religion und Technik. Seine prägnante Struktur vom einfachen Stamm bis zu den feinsten Verästelungen verleiht auch der abstraktesten Mathematik dank Computersimulation und moderner Drucktechniken die Illusion naturnaher Sinnlichkeit. Das Baumbild vereinfacht komplexe Zusammenhänge, es liefert populäre Erklärungsmodelle und schafft Ordnung. Die endlosen Variationsmöglichkeiten werden in dieser Ausstellung unter drei Themenbereichen abgehandelt: Wachstum - Ordnung Austausch. Die bewussten und auch unbewussten Implikationen der dendritischen Form sind das zu ergründende Thema der reichhaltigen und ästhetisch ansprechenden Beispiele. Oder im Ausstellungskatalog nachzulesen: «Wann immer ein Wissenschaftler den Stift aufs Papier setzt (oder durch die Linse schaut, oder zur Com-

\section{Abbildung 1}

Myxobakterien mit sogenannten Fruchtkörpern (eingefärbtes Mikrofoto). (C Gesellschaft für Biotechnologische Forschung, Braunschweig/D, Heinrich Lünsdorf.

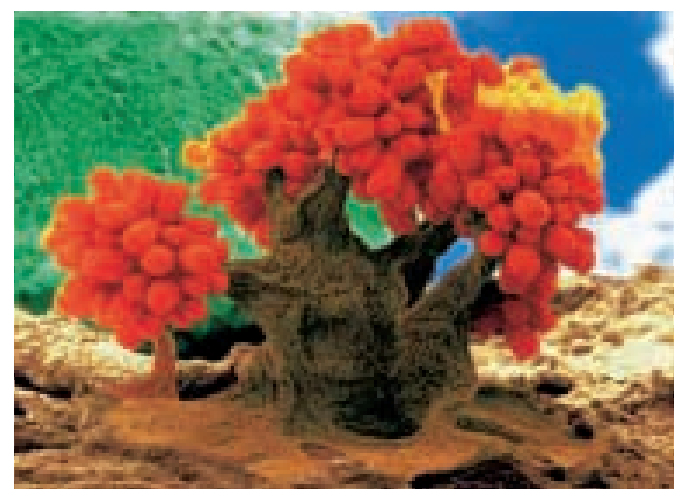

putermaus greift), entsteht das daraus hervorgehende Bildmaterial nicht in einem Vakuum der reinen Logik und Funktionalität - es ist Bestandteil einer umfassenden visuellen Kultur, in der auf der glitschigen Oberfläche von Metapher, Anspielung und Analogie Wörter und Bilder sich drängeln, einander infiltrieren und miteinander kollidieren.»

Ob Schneekristalle, fraktale Geometrie, Myxobakterien in der Rasterelektronenmikroskopie, Strukturformeln der anorganischen Chemie, Wasserläufe, Evolutionsmodelle, linguistische Baumdiagramme, Enzyklopädien von Diderot und d'Alembert oder Verzeichnisstrukturen elektronischer Dateimanager, immer begegnen wir dem Baumprinzip (Abb. 1).

Ausführlich werden die Typologien neuronaler Dendriten und ihre Vielfalt an Formen und Funktionen gezeigt. Gerade in der Hirnforschung haben Bilder eine zentrale Bedeutung: von Cajals Färbetechnik bis zu den konfokalen Mikroskopaufnahmen, deren zweidimensionale Schichtbilder die Neuronenzelle räumlich erkennen lassen. Digitale Rekonstruktionen nach vordefinierten Algorithmen lassen die gleichen Zellen wie kahle Äste in den Raum wachsen oder dank eingebauter biofluoreszenter Moleküle im Laserlicht aufleuchten.

Der Baum scheint eine universal gültige Metapher zu sein, die vom Nanobereich bis zur kosmologischen Grösse Unvergleichliches und Gegensätzliches visuell-symbolisch vereinigt. Darin liegt eine ungeheure Faszination und Verführung zugleich. Denn gerade weil diese Bilder scheinbar einfach verständlich und natürlich wirken, können sie auch wirksam, über falsche Analogien und implizite Wertungen, wissenschaftliche Erkenntnisse blockieren. Irgendwann wird auch hier ein reinigender Bildersturm die falschen Ikonen hinwegfegen. Abgesehen vom grossen Sehvergnügen sind diese Einsichten nur einige wenige Beispiele von vielen Lernergebnissen, die das Museum für Gestaltung in verdankenswerter Weise ermöglicht.

Als letzter Anlass in den Ausstellungsräumen wird am 24. August 2005 um 20 Uhr das Thema durch ein Gespräch vertieft: «Verführerische Bilder - Wissenschaft und Medien», u.a. durch Prof. Dr. Michael Hampe, Philosoph, ETH Zürich; Moderation: Arabelle Frey, Redaktion Sternstunde SF DRS. 